should be extended to other sections of the community. With ten more occupational psychologists in the Ministry of Labour, considerable help could be given in providing better guidance for both adults and young people. To avoid real human waste, however, the training people received for jobs should be given the widest possible base, and specialization should be postponed as long as possible, until the individual and his advisers are reasonably sure he is in the right occupation or profession.

\section{Nature Reserves}

Tre forty-fourth annual report of the Society for the Promotion of Nature Reserves for the year ending March 31 is largely made up of accounts of the activities at the fourteen reserves which come under the jurisdiction of the Society (Pp. 44+2 plates. London: Society for the Promotion of Nature Reserves, British Museum (Natural History), 1961. 10s.). At Woodwalton Fen, Huntingdonshire, a study of the breeding biology of the large copper butterfly was continued and the eggs and larvæ on more than a thousand food-plants are being counted at regular intervals. Observations will be carried out on the proference shown by the butterflies when egg-laying for docks growing in the open fen and those growing in the dykeside. Suggestions for introducing the butterfly on an experimental basis to Blackmoor Copse Nature Reserve, Wiltshire, have been considered, but it has now been decided to postpone a decision until further observations have been made at Woodwalton Fen. A spider new to the British list, Asagena phalerata, was recorded at Linwood Warren Nature Reserve, while at Calf of Man, Isle of Man, a red-breasted flycatcher (the second Manx record) was captured in June, and Manx shearwaters were taken on land during the summer. The Manx shearwater has not been seen on the island for nearly two hundred years. At Belfairs Great Wood, Essex, the reed mace grass veneer (Crambus paludellus Hübner) has now occurred two years running in a garden abutting on the Reserve, and is probably breeding on reed mace in one of the small ponds.

\section{Electrotechnology in Australia}

Is the annual report of the Division of Electrotechnology of the Australian Commonwealth Scientific and Industrial Research Organization for the year ended June 30,1960 , reference is made to the threeweeks visit paid by Prof. H. Fröhlich, professor of theoretical physics in the University of Liverpool. to Australia at the invitation of the Division. The object of the visit was to discuss and advise on the various aspects of the research work of the Dielectrics Section of the Division, which is concerned with the study of the alkali halides, aliphatic long-chain compounds-particularly the growth of large single crystals and the production of pure compounds; the hydrates of calcium sulphate; and the theories of dielectric loss and of superconductivity. The Division is responsible for the maintenance of the Common. wealth standards of measurement of electrical and magnetic quantities, and its activities are dealt with separately in the annual report under the headings of direct current, power frequency, sudio- and radiofrequency, and magnetics. With the completion of the calculable capacitor, considerable progress has been made with necessary additional equipment and techniques for the absolute determination of the $\mathrm{ohm}$. The screening efficiency of screened rooms with especial emphasis on the microwave region of the spectrum has been investigated, and work on the probability problems associated with various random processes has been carried out experimentally by means of the probability distribution analyser designed and constructed in the Division. The report concludes with a list of the publications by members of the staff, and their names and positions as at June 30, 1960.

\section{Solid Propellant Test Rig}

Messis. P. A. Hilton AND Co., engineers, of Radlett, Hertfordshire, announce that they have completed the development of a solid propellant rocket motor test rig for use in universities and technical colleges. The rig consists of a stainless steel rocket motor suspended on a swinging parallel motion linkage which pushes against a cantilever spring beam. Movement under load is transmitted to a pen recorder indicating thrust, on paper moved at constant speed by a synchronous electric motor. The area of the diagram produced is related by the calibration to the total impulse. Chamber pressure is transmitted by flexible pipe to a bourdon tube which in turn operates a recorder pen running parallel with the thrust pen. The fuel used is a form of cordite supplied in cartridge form giving a specific impulse of about 180 sec. and requiring no more elaborate storage facilities than are accorded to shotgun ammunition. The motor is equipped with a blow-out diaphragm to diminish explosion risks. The rig permits measurement of thrust, total impulse, specific impulse and burning time, and it is possible to study the effect of chamber pressure and nozzle design on these quantities by substituting nozzles of different diameters and profiles.

The rig is of simple design, of which the recorder is the weakest link, since it is not cortain that the relation between diagram area and total impulse is strictly linear and since the mechanism for applying tension to the paper is rather crude. The rig, however, should prove valuable for teaching and demonstrating in engineering departments wherever an interest in rocket motors and combustion exists and it has been constructed on a scale such that departments with quite limited faci'ities can use it. The rig is a welcome addition to the very limited range of standard teaching apparatus available in the sphere of gas dynamics and combustion. Further details can be obtained from the manufacturers.

\section{Summer School in Analytical Chemistry}

THE fifth triennial summer school in analytical chemistry, organized by the Royal Institute of Chemistry with the participation of the Society for Analytical Chemistry, will be held in the Manchester College of Science and Technology during September 9-15, 1962. The School will consist of four separate, but concurrent, courses: Course 1,"Physical Methods of Organic Chemistry", under the direction of Dr. D. W. Mathieson, reader in pharmaceutical chemistry, School of Pharmacy, London; Course 2, "Recent Developments in Inorganic Analysis", under the direction of Mr. W. T. Elwell, chief analyst, Imperial Chemical Industries, Ltd., Metals Division, Witton, Birmingham; Course 3, "The Determination of Toxic Substances in the Air and in Effluents", under the direction of Mr. H. E. Stagg, chief analyst, Imperial Chemical Industries, Ltd., Dyestuffs Division, Black. ley, Manchester; Course 4, "Newer Instrumental Techniques", under the direction of Dr. V.S. Griffiths, reader in spectroscopy, Battersea College of Tochno- 